\title{
Energy Management and Power Control for a Grid-Connected PMSG Wind Energy Conversion System with Extra Function of Harmonic Elimination for Local Nonlinear Loads
}

\author{
Ali Tahmasebi Sohi ${ }^{1}$, Shahram Javadi ${ }^{2}$, SZ Moussavi $^{3}$ \\ ${ }^{1}$ (M.Sc. Student, Department of Electrical Engineering, Central Tehran Branch, Islamic Azad University, \\ Tehran, Iran, Email:alitahmasbisohi@yahoo.com) \\ ${ }^{2}$ (Assistant professor, Department of Electrical Engineering, Central Tehran Branch, Islamic Azad University, \\ Tehran, Iran, Corresponding Author, Email: sh.javadi@iauctb.ac.ir) \\ ${ }^{3}$ (Assistant Professor, Electrical and Computer Engineering, Shahid Rajaee Teacher Training University, \\ Tehran, Iran, Email: smoussavi@srttu.edu)
}

\begin{abstract}
Wind energy conversion maximum power extracting along with power quality issues both play a crucial role in the power systems. This paper demonstrates the feasibility of using a new controlling method for simultaneously performing the maximum power point tracking and decreasing grid current total harmonic distortion (THD) as an extra function in wind energy conversion using permanent magnet synchronous generator (PMSG). While enhancing the grid power quality using proposed method, an improved maximum power point tracking (MPPT) algorithm based on optimum torque controlling is employed. Resorting this improved algorithm increases MPPT efficiency to be higher than 97\% in all operation modes. In this study, a $P M S G$ wind energy conversion with nominal power of $20 \mathrm{KW}$ at wind speed of $9 \mathrm{~m} / \mathrm{s}$ is considered for simulation. This system is connected to the local nonlinear load and the grid. Simulation results including MPPT dynamic and steady state behaviors in three different wind speeds and THD analyzing in presence and absence of harmonic elimination extra function show impressive benefits of the proposed method.
\end{abstract}

Keywords: wind energy conversion, permanent magnet synchronous generator, harmonic elimination, maximum power point tracking

\section{Introduction}

It goes without saying that renewable energy exploitations have become one of the most pressing concerns facing all electrical engineers. The conventional fossil fuels depletion and environmental pollution go hand-in-hand for making a growth in renewable energy usage. These main reasons make researchers be fully aware to supply electrical power requirements from renewable energy resources including wind energy and photo-voltaic (PV) systems [1], [2]. Furthermore, renewable energy sources have some enormous advantages including high capability of using wide range power exploitation, low price of produced power and no need of water or other fluids [3].

In the previously mentioned renewable energy sources, considerable attention has been paid to the wind energy conversion systems (WECSs). WECSs have been utilized in many areas especially in addressing the electrical power demands of impassable regions. Accordingly, various technologies in all related fields have been improved for them. Permanent-magnet synchronous generator (PMSG) generation system shows a major trend in development of wind power applications due to its considerable advantages. Using this Permanentmagnet synchronous generator eliminate the need for the multi-level gear box, reduce the maintenance cost and increase the system total energy [1]-[6].

The connection of a wind turbine to the grid is a delicate issue. In fact, the power production of largepower wind turbines could create some difficulties to the transmission line designed for constant power and to the power system stability. This important issue justifies the concerns related to increasing penetration of wind energy within the power system [5]. However, with adopting some technical arrangements such as controlling the injected power to the grid, these problems could be easily removed. Accordingly, controlling the injected power in the grid-connected wind energy conversion systems (GCWECSs) has a paramount of importance due to grid demand necessities. In addition, harvesting maximum power from wind and feeding the grid with highquality electricity are two main aspects for GCWECSs. Although there are some direct ac-ac converters used in GCWECSs, based on these two key factors the ac-dc-ac converters are more suitable choice [2]-[8].

Fig. 1 shows a conventional configuration of ac-dc-ac topology for PMSG. This configuration includes diode rectifier, boost dc-dc converter and three-phase inverter. The generator voltage is rectified with a diodebridge. Then a fully controlled inverter is adopted to connect the system to the grid. Hence a full-scale back-to- 
back power converter is needed. In recent researches, the use of a synchronous generator with full-power backto-back converters is studied and appears to be the most successful configuration. In this topology, boost converter is controlled for maximum power point tracking (MPPT) and inverter is controlled to deliver highquality power to the grid [5]-[13].

In recent years a great effort has been devoted to the study of maximum power point tracking (MPPT) algorithm in GCWECSs. To the author knowledge, the most popular MPPT algorithms which are recently considered are including tip speed ratio (TSR) control, power signal feedback (PSF) control, perturb and observe (P\&O) control and optimum torque control [14]-[17]. With regard to the fact that TSR is constant in all wind speed, in TSR algorithm, TSR should be maintained in its optimum value. Therefore with using the error signal of optimum TSR and real TSR, control signals can be chosen in such a way to decline the error signals. In PSF method, at first optimum power with respect to rotational speed should be evaluated as a look-up table. Then by comparing the optimum power with real power, harvesting maximum power can be readily achieved. In P\&O procedure, MPPT can be obtained using an iterative technique. In this technique the previous-step power is compared with now-step power and the operating point is evaluated. Based on this operating point, the control signal would be selected. This algorithm would be performing till the operating point reaches maximum power point. Optimum torque control is based on PMSG torque. The error signal of PMSG optimum and real torques can be used as a controlling signal to extract maximum power. Due to its robustness and low oscillation in comparison with aforementioned algorithms, the authors prefer to employ this technique and apply it to the interface DC-DC boost converter [14]-[17].

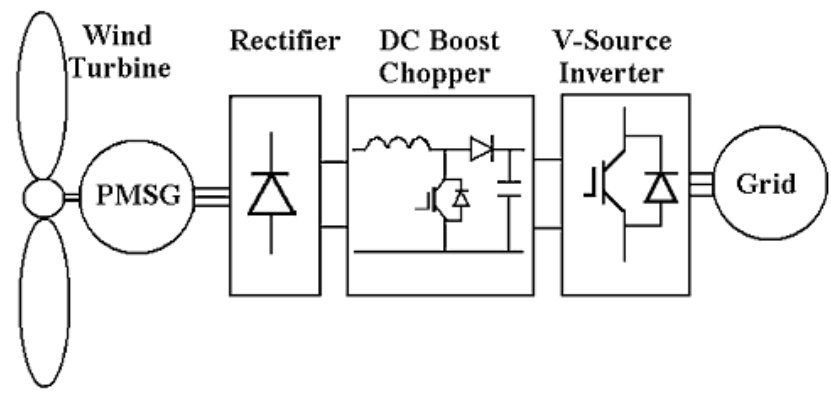

Fig. 1. Conventional PMSG-based WECS with dc-dc boost converter.

In recent years, with the increase of nonlinear loads such as variable-frequency drives and high current rectifier drawing non-sinusoidal currents, power quality distortion has become a serious problem in electrical power systems. Harmonics presence leads to some major problems including disturbance to electric and electronic devices, higher losses, extra neutral current, improper working of metering devices, de-Rating of distribution equipment and resonance problem. These loads are typically composed of odd harmonic currents, which are multiples of the fundamental frequency. The harmonic currents cannot contribute to active power and need to be eliminated to improve power quality [18]. Although active power filters (APFs) are designed for this purpose, in GCWECSs the grid-side inverter playing the role of injecting power to the grid can be employed to eliminate harmonics as an extra function. Using this added function, there would be a significant reduction in investment cost. The over inverter capacity in the low speed wind would be used for current harmonics elimination. This paper presents a method to use the grid-side inverter in order to both control power injection and eliminate high-order harmonics.

The remainder of the paper is organized as follows. In the following section control system and its modeling will be discussed. Section III is devoted to discuss system layout and its features. The simulation and its results are entirely discussed in section IV. Finally a conclusion of this work will be drawn.

\section{Control system}

The overall structure of the grid-connected wind energy conversion system is shown in Fig. 2. On the whole there are two main control parts:

1- Maximum power point tracking.

2- Control of power delivered to the grid.

As a matter of maximum power extracting, optimum torque control is employed owing to its robustness and low oscillation in comparison with aforementioned algorithms. This technique would be applied to the DC-DC boost interface converter. For controlling injected power to the grid, the conventional vector control will be resorted. Here these two parts would be independently discussed as following.

\section{A. Maximum Power Point Tracking}


The block diagram of optimum torque control is illustrated in Fig. 3. This controller extracts the maximum power through comparing the PMSG optimum and real torque.

The mechanical power delivering through wind is calculated by:

$$
\begin{aligned}
& P=\frac{1}{2} \rho \pi R^{2} C_{p} V_{w}{ }^{3} \\
& C_{p}(\lambda, \beta)=0.5176\left(\frac{116}{\lambda_{i}}-0.4 \beta-5\right) \cdot e^{\frac{-21}{\lambda_{i}}}+0.0068 \lambda
\end{aligned}
$$

Where $\rho$ is the air density, $R$ is the radius of turbine blades, $V_{w}$ is the wind velocity, and $C_{p}$ is the power coefficient defined as the ratio of turbine power to wind power and depends on the aerodynamic characteristics of blades. It can be proved that the maximum value of $\mathrm{C}_{\mathrm{p}}$ is limited to 0.56. For writing the equation (1) in terms of the rotor speed, we use following equation.

$V_{w}=\frac{\omega_{b} R}{\lambda}$

Where $\lambda$ is tip speed ratio. Therefore

$P=\frac{1}{2} \rho \pi R^{5} C_{p} \frac{\omega_{b}^{3}}{\lambda^{3}}$

Regarding above equation optimum power will be gathered provided that the power coefficient and the tip speed ratio are optimum. Accordingly

$$
\begin{aligned}
& P_{o p t}=\frac{1}{2} \rho \pi R^{5} \frac{C_{p}{ }^{o p t}}{\lambda^{o p t^{3}}} \omega_{b}^{3} \\
& T_{m}^{o p t}=\frac{1}{2} \rho \pi R^{5} \frac{C_{p}{ }^{o p t}}{\lambda^{o p t^{3}}} \omega_{b}^{2}=K^{o p t} \cdot \omega_{b}^{2}
\end{aligned}
$$

Now optimum torque is compared with real torque and its error signal is used for the interface DC-DC boost converter to harvest maximum power. This technique is straightforward and has a relatively high MPPT efficiency.

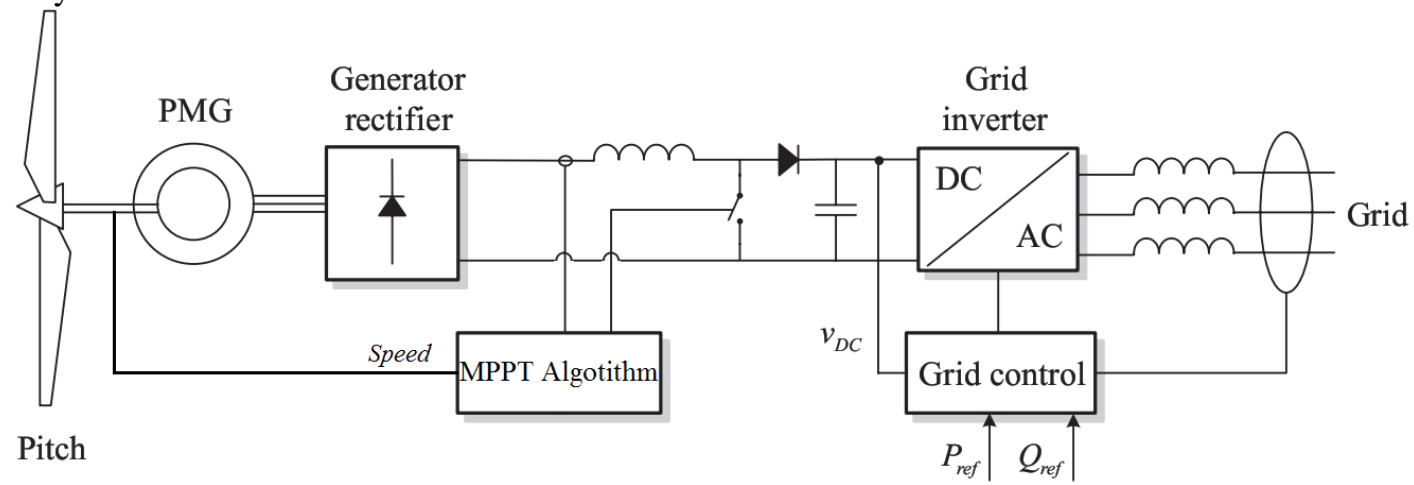

Fig.2. Overall structure of grid-connected wind energy conversion system.

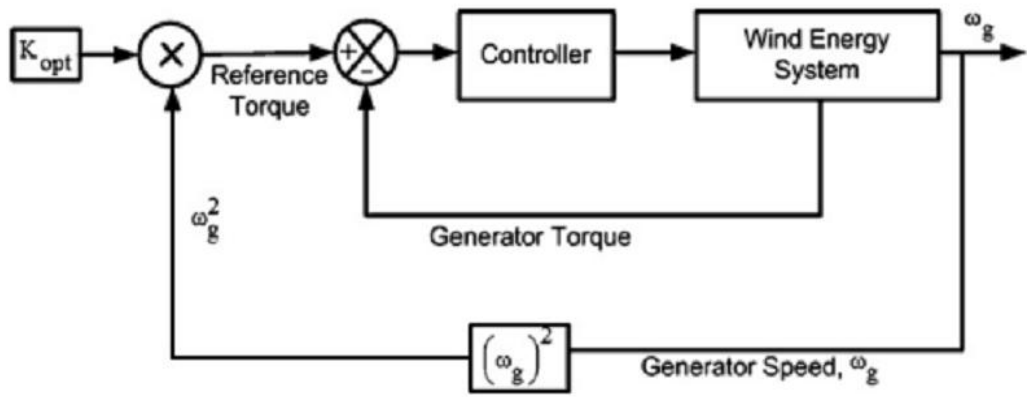

Fig. 3. Block diagram of optimum torque control 


\section{B. Control of Power Delivered to the Grid}

Grid-tied generator is an electrical energy source including all needed interface units and operating in parallel with the distribution network [10]-[13]. Although some energy sources can be connected directly to the distribution network, but in the case of DC power sources or variable speed wind turbine (VSWT) systems it is necessary to use a power converter that interfaces the source and the grid. Due to the simplicity of vector controlling, here $\mathrm{d}-\mathrm{q}$ axis theory is employed for power controlling.

The power equations in the synchronous reference frame are given by [19]

$P=\frac{3}{2}\left(v_{d} i_{d}+v_{q} i_{q}\right)$

$Q=\frac{3}{2}\left(v_{q} i_{d}-v_{d} i_{q}\right)$

Where $\mathrm{P}$ and $\mathrm{Q}$ are active and reactive power respectively, ' $\mathrm{v}$ ' is grid voltage and ' $\mathrm{i}$ ' is the current injected to the grid. The subscripts " $\mathrm{d}$ " and "q" stand for direct and quadrature components respectively. " $\mathrm{v}_{\mathrm{q}}$ " will be equal to zero providing that the reference frame is oriented along the grid voltage. Accordingly, active and reactive power may be expressed as

$$
\begin{aligned}
P & =\frac{3}{2} v_{d} i_{d} \\
Q & =-\frac{3}{2} v_{d} i_{q}
\end{aligned}
$$

According to the above equations, active and reactive power control can be achieved by independently controlling direct and quadrature current components respectively.

These parameters can be controlled as the following paths. With the specified reactive power, the qaxis current reference is set. To acquire unit power factor, the q-axis current reference should be set to 0 . However, in the extra function state this current should be set such a way that eliminates the higher order harmonics (with opposite sign of current harmonics drawn by local nonlinear load). For injecting maximum power to the grid, an outer capacitor voltage control loop (adjusting dc-link at its desired value) is used to set the d-axis current reference for active power control. This guarantees that all the power coming from the rectifier is transferred to the grid.

\section{System Specifications}

Although tracking the maximum power is absolutely important, in this study the prominent factor is to enhance the THD resulted from local non-linear load. The overall schematic of simulated GCWECS is illustrated in Fig. 4(a). According to this figure, power injecting control is performed in the d-q reference frame. A non-linear load is connected to grid near the wind turbine location leading to draw nonlinear current. At first this non-linear load current is transferred to d-q reference frame and because the angular position is acquired from grid voltage through a PLL, the d-axis current would be the representative of active power while q-axis one represents reactive power. Accordingly it is clear that by adjusting q-axis current, the reactive power drawn with three-phase rectifier can be eliminated. With performing this mechanism, the grid current THD would be significantly declined. It should be mentioned that if a selective harmonic elimination is required, we would be able to use a band-pass filter in q-axis current to pass only considered harmonic for cancelling.

Additionally, Fig. 4(b) depicts the MPPT controlling system. As it can be easily seen, rectifier output voltage and current are used to extract maximum power based on equation (4). This method never applied to interface DC-DC boost converter. Therefore there is an aspect of novelty in addition to harmonic elimination as an extra function. As a case study and validation of new strategy, a wind turbine equipped with PMSG is considered. Their characteristics are listed in Table.1.

Table. 1. Wind Turbine and PMSG Parameter

\begin{tabular}{cc|cc}
\hline Wind Turbine Parameter & Value & PMSG Parameter & Value/Type \\
\hline Turbine Blade Radius & $4.3 \mathrm{~m}$ & Phase Number & 3 \\
Cut-in speed & $2 \mathrm{~m} / \mathrm{s}$ & Rotor Type & Round \\
Cut-off speed & $15 \mathrm{~m} / \mathrm{s}$ & Stator Resistance & $0.895 \Omega$ \\
Turbine efficiency & 0.905 & Stator Inductance & $12.45 \mathrm{mH}$ \\
Air density & $1.225 \mathrm{Kg} / \mathrm{m}^{3}$ & Linkage Flux & $1.61 \mathrm{~V} . \mathrm{s}$ \\
- & - & Inertia & $1.47 \mathrm{Kg} / \mathrm{m}^{2}$ \\
\hline
\end{tabular}




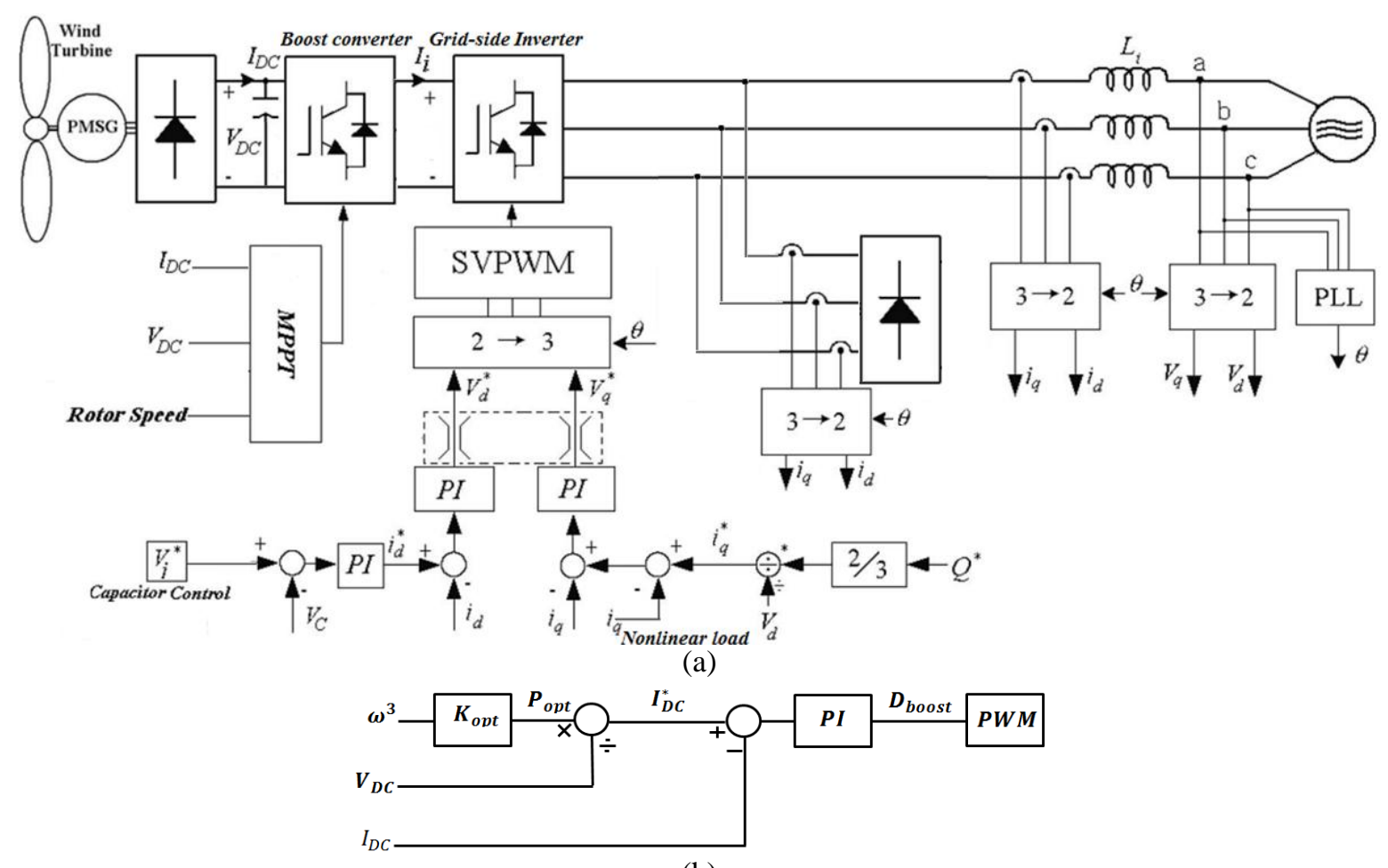

(b)

Fig.4. a) overall control system, b) MPPT algorithm implementation.

Moreover, the interface DC-DC boost parameters are given in Table.2. The calculation procedure of this converter is beyond this study and the interested readers are referred to [20]. Based on above mentioned objectives and the strategy depicted in Fig. 4, the PI coefficients in all controlling parts are obtained from system modeling and required dynamic response and listed in Table. 3.

It should be mentioned that the grid line-to-line voltage and its frequency are $380 \mathrm{~V}$ and $60 \mathrm{~Hz}$ respectively. For being able to inject reactive power to the grid, it can be proved that the Link-DC voltage should be fixed near $800 \mathrm{~V}\left(1.5^{*} 380^{*} 1.41\right)$. Therefore, $\mathrm{V}_{\mathrm{i}}$ reference is constant and equal to $800 \mathrm{~V}$.

Table. 2. DC-DC Boost Parameters

\begin{tabular}{cc}
\hline DC-DC Boost Parameters & Value/Type \\
\hline Inductance & $5 \mathrm{mH}$ \\
Input Capacitance & $1 \mathrm{mF}$ \\
Output Capacitance & $12 \mathrm{mF}$ \\
Switching Frequency & $100 \mathrm{KHz}$ \\
\hline & \\
Table.3. Current and Voltage Regulators Parameters \\
\hline Regulators Parameters & Value/Type \\
\hline MPPT-K & 0.0031 \\
MPPT-K & 0.00018 \\
Inverter Link DC-K & 10 \\
Inverter Link DC- $\mathrm{K}_{\mathrm{i}}$ & 800 \\
d-axis Current Regulator- $\mathrm{K}_{\mathrm{P}}$ & 0.3 \\
d-axis Current Regulator $-\mathrm{K}_{\mathrm{i}}$ & 20 \\
q-axis Current Regulator- $\mathrm{K}_{\mathrm{P}}$ & 0.3 \\
q-axis Current Regulator $-\mathrm{K}_{\mathrm{i}}$ & 20 \\
\hline
\end{tabular}

\section{Simulation Results}

The wind speed pattern applying to the considered system is depicted in Fig. 5. These speeds are in cutin/off limitation. For wind speed of 7, 9 and $11 \mathrm{~m} / \mathrm{s}$, the corresponding turbine powers are 5.3, 11.05 and 18.5 KW respectively. Based on equation (1), optimum CP is evaluated around 0.47. Fig. 6 demonstrates the PMSG output power versus its rotor speed. It is clear that the MPPT algorithm should perform in such way to make rotor speed be in desired value for catering maximum power harvesting. 


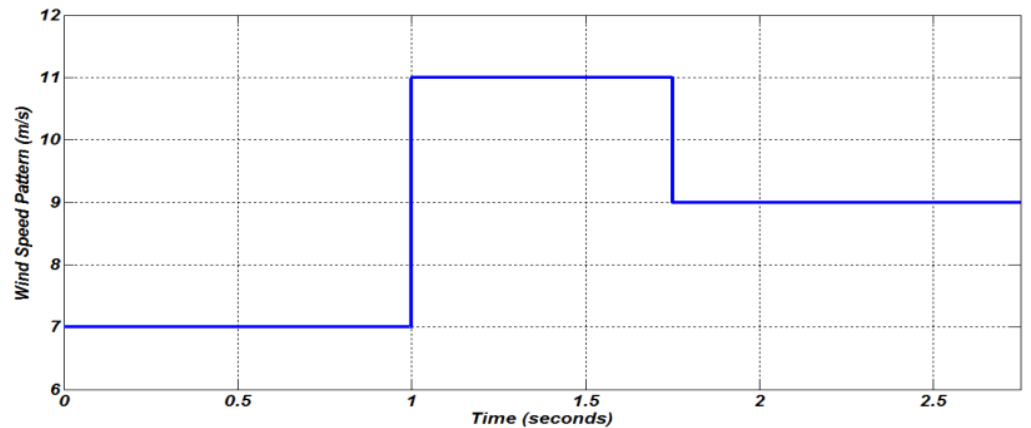

Fig.5. Considered wind speed pattern

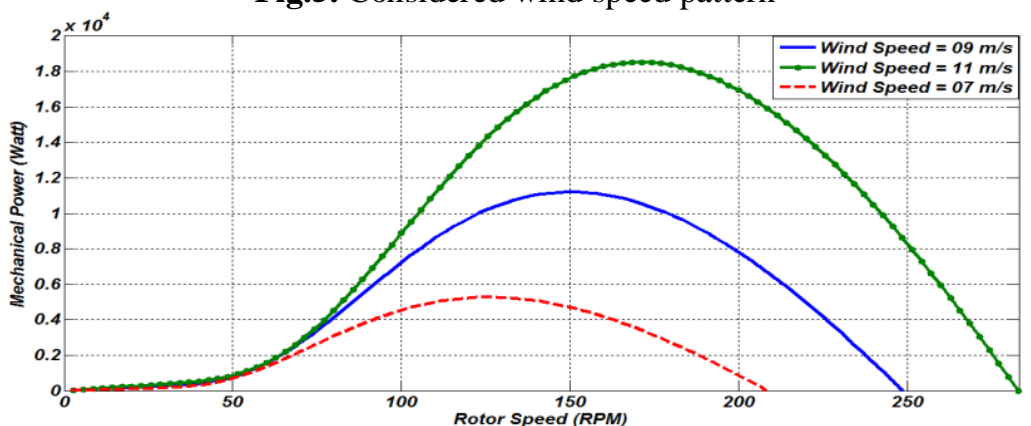

Fig.6. Mechanical Power versus Rotor Speed

The wind turbine output powers along with PMSG output power are both shown in fig. 7(a). The differences between these two powers are led from power loss in PMSG as well as turbine mechanical loss; Fig. 7 (b) demonstrates rotor speed tracking the optimum speed. For a quantative comparison, the expected and real power and speed values are listed in Table. 4.

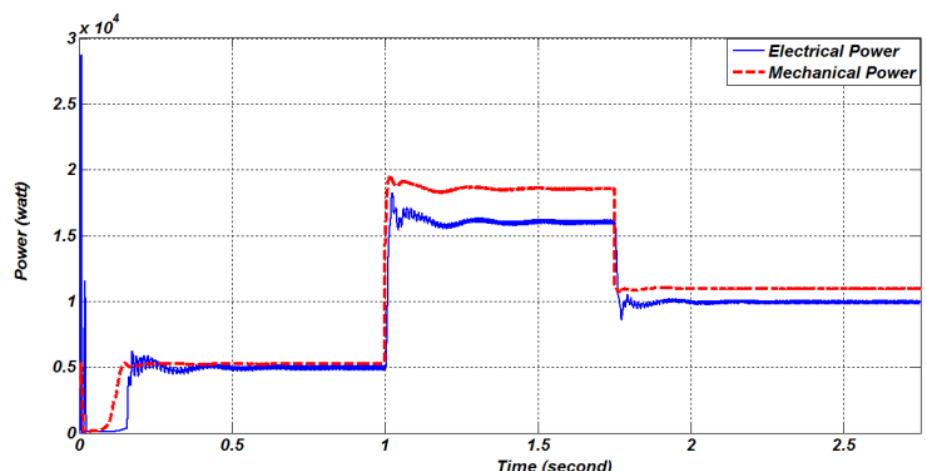

(a)

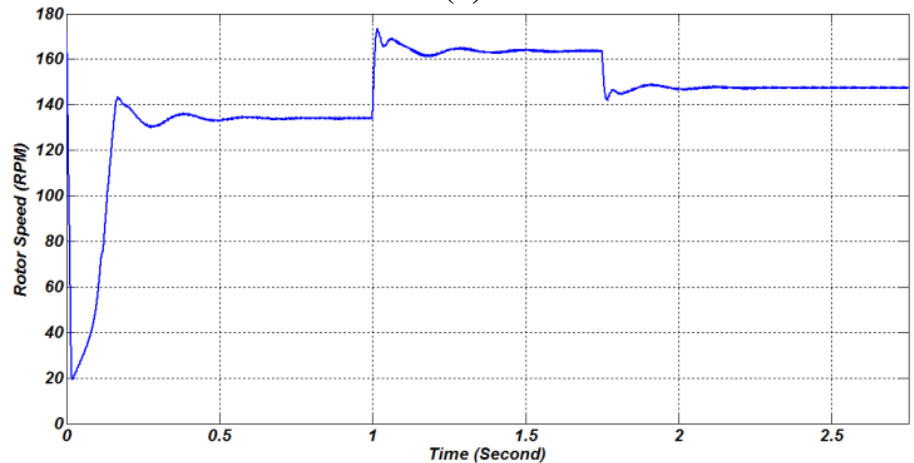

(b)

Fig. 7. a) Electrical and Mechanical Power, b) PMSG Rotor Speed. 
Energy Management and Power Control for a Grid-Connected PMSG Wind Energy ....

Table.4. MPPT Features Comparison Based On Rotor Speed Turbine Power.

\begin{tabular}{ccccc}
\hline Wind Speed & Optimum Rotor Speed & Real Rotor Speed & Optimum Turbine Power & Real Turbine Power \\
\hline $7 \mathrm{~m} / \mathrm{s}$ & $135 \mathrm{RPM}$ & $134 \mathrm{RPM}$ & $5.3 \mathrm{KW}$ & $5.1 \mathrm{KW}$ \\
$9 \mathrm{~m} / \mathrm{s}$ & $150 \mathrm{RPM}$ & $148 \mathrm{RPM}$ & $11.05 \mathrm{KW}$ & $11 \mathrm{KW}$ \\
$11 \mathrm{~m} / \mathrm{s}$ & $168 \mathrm{RPM}$ & $166 \mathrm{RPM}$ & $18.5 \mathrm{KW}$ & $18.1 \mathrm{KW}$ \\
\hline
\end{tabular}

Fig. 8 depicts the link-DC voltage. Regarding this figure the link-DC voltage is fixed around $800 \mathrm{~V}$. The maximum settling time overshoot in this voltage are limited to $0.55 \mathrm{sec}$ and $6 \%$ respectively. Therefore dynamic of proposed system is also robustness.

Fig. 9 demonstrates inverter output voltage and current. This figure is captured when the nonlinear load is not connected to the grid. Therefore current waveform is sinusoidal and low-harmonic. It is mentioned that in next part the nonlinear effects and proposed strategy would be discussed.

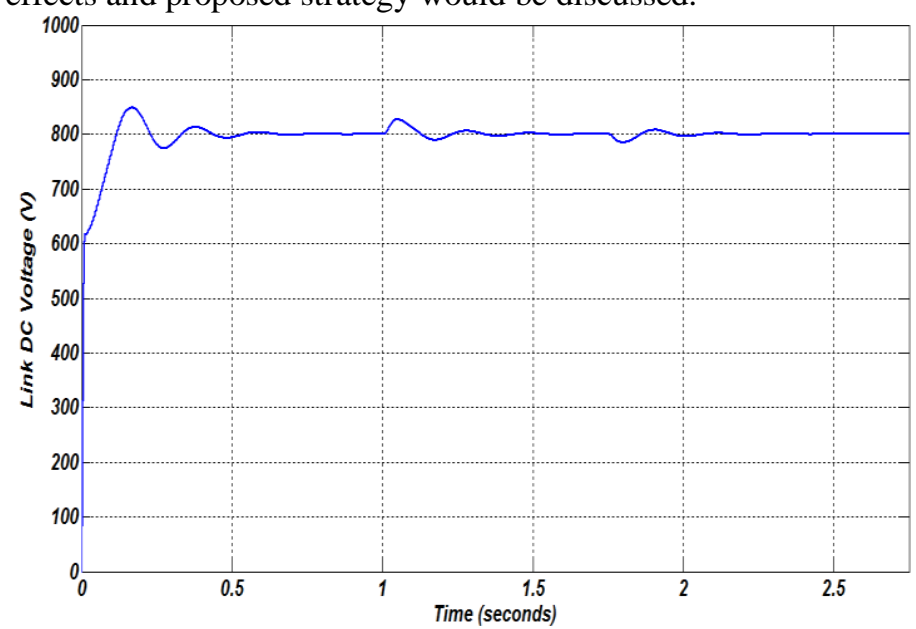

Fig.8. Link-DC Voltage During All Wind Speed.

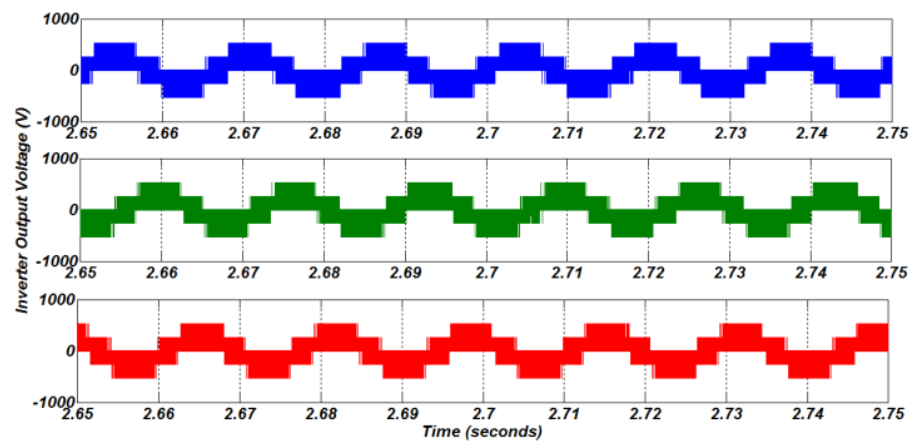

(a)

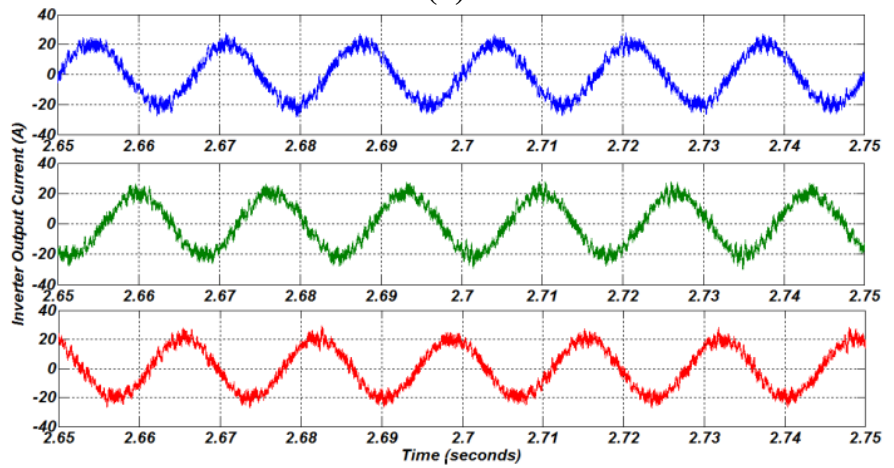

(b)

Fig. 9. a) Inverter Output Voltage, b) Inverter Output Current.

For discussing proposed strategy merit, it is considered that a nonlinear load is connected to the grid while the wind speed is around $9 \mathrm{~m} / \mathrm{s}$ and $11 \mathrm{KW}$ active power is injected to the grid. Aiming to have lowharmonic grid current, nonlinear load current has been sensed and then based on this current; this new method would be applied. With using nonlinear load q-axis current and subtracting this current from reference q-axis current, this method can be performed. 
Fig. 10 illustrates grid current waveform when the given strategy is not applied. As it is shown current THD is $63.47 \%$. This high THD leads to EMI problems for communication as well as reducing the capacity of power transferring. Behaviors of grid under same condition when the proposed strategy is employed are depicted in Fig. 11. With regard to this figure, THD has been reduced to 19.19\%. Accordingly, using GCWECS as a harmonic elimination added function without increasing the number of power electronic devices leads to near $42 \%$ THD reduction.
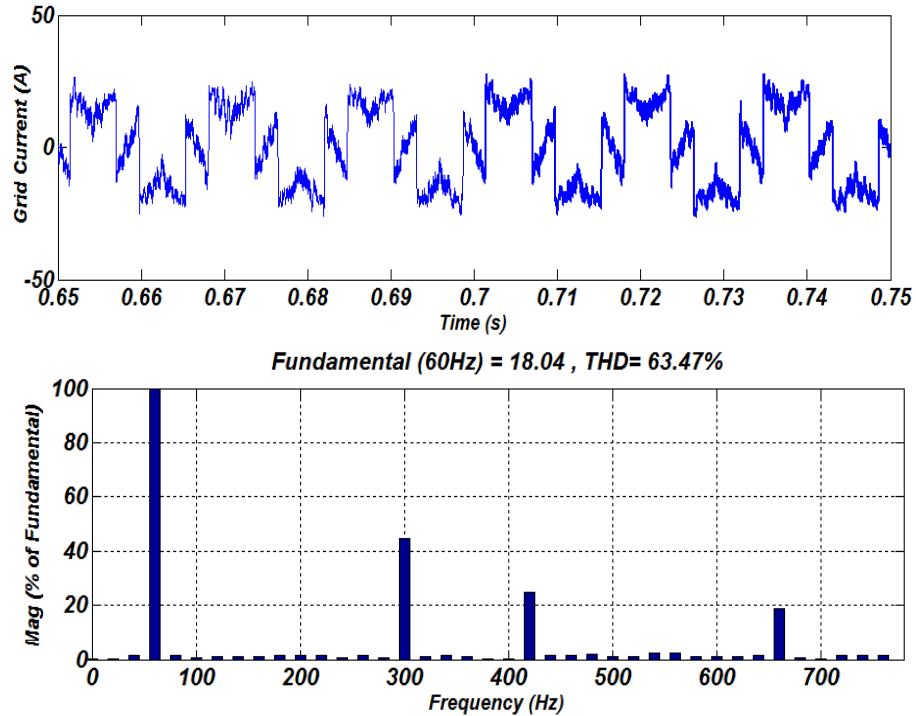

Fig.10. Grid current and its FFT analysis when proposed technique is not applied.
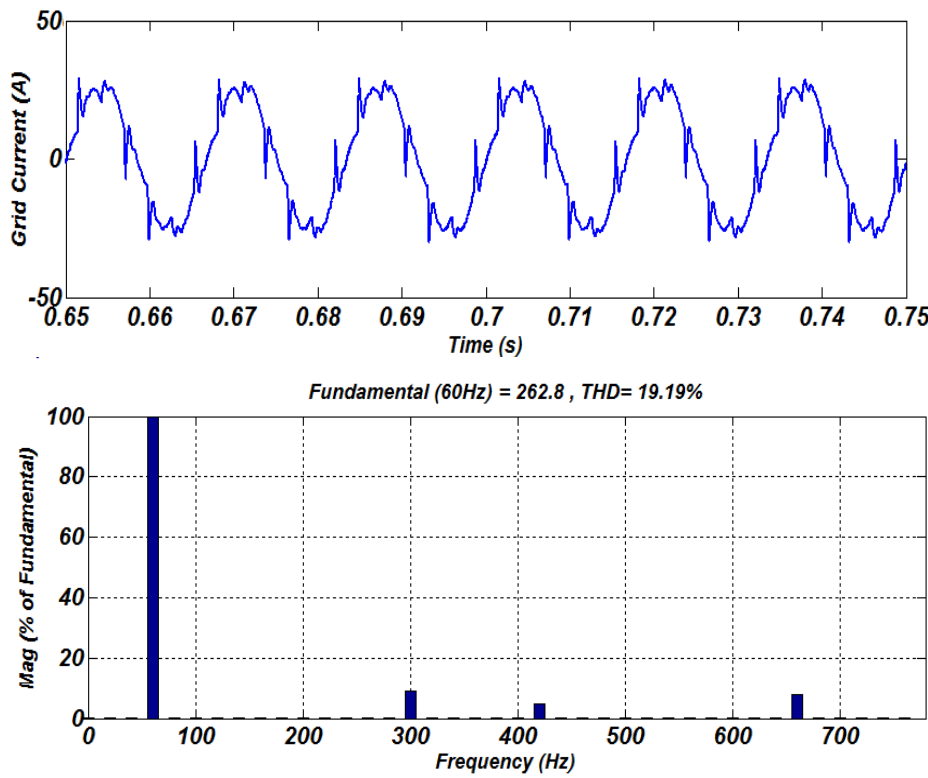

Fig.11. Grid current and its FFT analysis when proposed technique is applied.

\section{Conclusion}

A new grid-connected wind energy conversion system with current harmonic elimination as an extra function is presented. With employing this modified power controlling technique, the grid current harmonic reduction without employing any active power filters is achieved while a nonlinear load is connected to the grid. This is done with using q-axis current controlling by means of a voltage source inverter fired based on space vector modulation. Furthermore, a proposed MPPT algorithm based on optimum torque controlling is introduced and led to make MPPT efficiency at least around 97\%. This MPPT is performed thorough an interface DC-DC boost converter. The capability of extracting maximum power, controlling power flow and current harmonic elimination as an extra function creates possibilities for many manufacturers dealing with nonlinear load to use GCWECSs as an extra electrical energy source.

\section{Acknowledgement}

The authors thank Islamic Azad University Central Tehran Branch for all helps and supports. 


\section{References}

[1] Teodorescu R., Liserr M., Rodriguez P., "Grid Converters For Photovoltaic And Wind Power Systems", Chapter 6 , Pages.127-153

[2] Blaabjerg F., Chen Z., "Power electronics for wind turbines", Chapter 3.

[3] BU He R, XUE Yu, "Grid Connection Control and Simulation of PMSG Wind Power System Based On Three Level NPC Converter", International Journal of Automation and Power Engineering (IJAPE) Volume 2 Issue 4, May 2013,pages.192-193.

[4] Pierluigi Tenca , Andrew A. Rockhill, Thomas A. Lipo, "Wind Turbine Current-Source Converter Providing Reactive Power Control and Reduced Harmonics", IEEE Transactions On Industry Applications, VOL. 43, NO. 4, JULY/AUGUST 2007.pages 1050-1051

[5] R. Swisher, C. R. DeAzua and J. Clendenin, "Strong winds on the horizon: wind power comes of age", Proc. IEEE, vol. 89, no. 12 pp. 1754-1764, Dec. 2001.

[6] J. Marques, H. Pinheiro, H. A. Gründling, J. R. Pinheiro and H. Hey, "A survey on variable speed wind turbine system", Congresso Brasileiro de Eletr^onica de Pot”enci(COBEP),2003, Fortaleza - CE.

[7] J. F. Conroy and R. Watson, "Low-voltage ride-through of a full converter wind turbine with permanent magnet generator",IET Renewable Power Generation, vol. 1, pp. 182-189, September 2007.

[8] S. Muller, M. Deicke and R.W. De Doncker, "Doubly fed induction generator systems for wind turbines," IEEE IndustryApplications Magazine, Vol. 8, Iss. 3, pp: 26 -33, May-June 2002.

[9] J. A. Baroudi, V. Dinavahi, A. M. Knight, "A Review Of Power Converter Topologies For Wind Generators", pages 457-460 .

[10] Fang Zheng Peng, "Z-Source Inverter", IEEE Transactions On Industry Applications, VOL. 39, NO. 2, MARCH/APRIL 2003.

[11] Aleksandar Nikolic , Borislav Jeftenic," Current Source Converter Topologies for PMSG Wind Turbine Applications", 14th International Power Electronics and Motion Control Conference, EPE-PEMC 2010.

[12] Seyed Mohammad Dehghan, Mustafa Mohamadian, Ali Yazdian Varjani, "A New Variable-Speed Wind Energy Conversion System Using Permanent-Magnet Synchronous Generator and Z-Source Inverter”, IEEE Transactions On Industry Applications, VOL. 24, NO. 3, SEPTEMBER 2009.

[13] Lauris Bisenieks, Dmitri Vinnikov, Ilya Galkin, "New Converter for Interfacing PMSG based Small-Scale Wind Turbine with Residential Power Network ",.

[14] K.Iimori, K.Shinohara, M.Muroya, Y.Matsusita, "Zero-Switching-Loss PWM Rectifier of Converter without DC Link Components for Induction Motor Drive", Proc of PCC-Osaka 2002, pp.I-6, 2002.

[15] A. G. Abo-Khalil and D. C. Lee, "MPPT control of wind generation systems based on estimated wind speed using SVR," IEEE Trans. Ind. Electron., vol. 55, no. 3, pp. 1489-1490, Mar. 2008.

[16] E. Koutroulis and K. Kalaitzakis, "Design of a maximum power tracking system for wind-energy-conversion applications," IEEE Trans. Ind. Electron., vol. 53, no. 2, pp. 486-494, Apr. 2006.

[17] X. Yuan, F.Wang, D. Boroyevich, Y. Li, and R. Burgos, "DC-link voltage control of a full power converter for wind generator operating in weakgrid systems," IEEE Trans. Power Electron., vol. 24, no. 9, pp. 2178-2192, Sep. 2009.

[18] M. Depenbrock, “A generally applicable tool for analyzing power rela- tions,” IEEE Trans. Power Syst., vol. 8, no. 2, pp. 381-387, May 1993.

[19] M. Chinchilla, S. Arnaltes, and J. C. Burgos, "Control of permanent- magnet generators applied to variable-speed wind-energy systems con-nected to the grid," IEEE Trans. Energy Convers., vol. 21, no. 1, pp. 130-135, Mar. 2006

[20] Erickson RW, Maksimovic D. Fundamentals of power electronics. 2nd ed. Norwell, MA: Kluwer; 2001. 